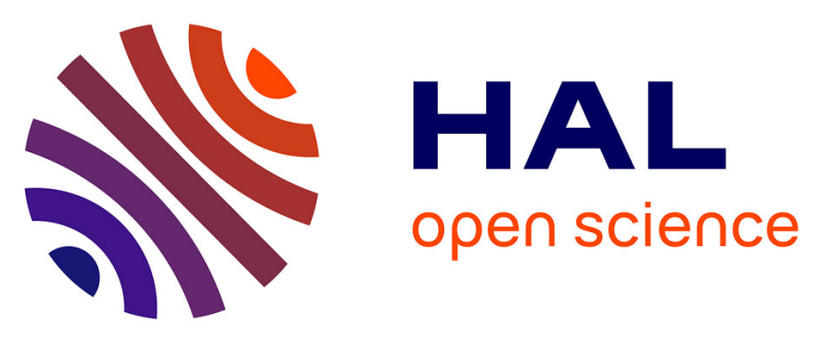

\title{
Proteinase-activated receptor-4 evoked colorectal analgesia in mice: an endogenously activated feed-back loop in visceral inflammatory pain
}

\author{
Anita Annahazi, Marta-Ewa Dabek, K Gecse, Christel Cartier, Arnaud \\ Polizzi, A. Rosztoczy, R Roka, T Wittmann, Vassilia Theodorou, Lionel \\ Bueno, et al.
}

\section{To cite this version:}

Anita Annahazi, Marta-Ewa Dabek, K Gecse, Christel Cartier, Arnaud Polizzi, et al.. Proteinaseactivated receptor-4 evoked colorectal analgesia in mice: an endogenously activated feed-back loop in visceral inflammatory pain. Neurogastroenterology \& Motility, 2012, 24 (1), pp.76-85. 10.1111/j.13652982.2011.01805.x . hal-01228309

\section{HAL Id: hal-01228309 \\ https://hal.science/hal-01228309}

Submitted on 12 Nov 2015

HAL is a multi-disciplinary open access archive for the deposit and dissemination of scientific research documents, whether they are published or not. The documents may come from teaching and research institutions in France or abroad, or from public or private research centers.
L'archive ouverte pluridisciplinaire HAL, est destinée au dépôt et à la diffusion de documents scientifiques de niveau recherche, publiés ou non, émanant des établissements d'enseignement et de recherche français ou étrangers, des laboratoires publics ou privés. 


\title{
Proteinase-activated receptor-4 evoked colorectal analgesia in mice: an endogenously activated feed-back loop in visceral inflammatory pain
}

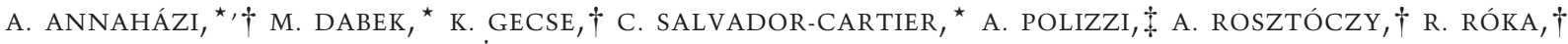 \\ V. THEOdorou, ${ }^{\star}$ T. WITTMANN, ${ }^{\dagger}$ L. BUENO ${ }^{\star} \&$ H. EUTAMENE ${ }^{\star}$ \\ *Toxalim UMR 1331 INRA/INP/UPS Neuro-Gastroenterology \& Nutrition Unit, Toulouse, France \\ $\dagger$ First Department of Medicine, University of Szeged, Szeged, Hungary \\ $\$$ Toxalim UMR 1331 INRA/INP/UPS Pharmacology Unit, Toulouse, France
}

\begin{abstract}
Background Activation of proteinase-activated receptor-4 (PAR-4) from the colonic lumen has an antinociceptive effect to colorectal distension (CRD) in mice in basal conditions. We aimed to determine the functional localization of the responsible receptors and to test their role in two different hyperalgesia models. Methods Mice received PAR-4 activating peptide (PAR-4-AP, AYPGKF-NH2) or vehicle intraperitoneally (IP), and abdominal EMG response to $C R D$ was measured. The next group received PAR-4$A P$ intracolonically (IC) with or without 2,4,6-triaminopyrimidine, a chemical tight junction blocker, before CRD. The SCID mice were used to test the role of lymphocytes in the antihyperalgesic effect. The effects of PAR-4-AP and PAR-4-antagonist (P4pal-10) were evaluated in water avoidance stress (WAS) model and low grade 2,4,6-trinitrobenzene sulfonic acid (TNBS) colitis. Spinal Fos protein expression was visualized by immunohistochemistry. Key Results The antinociceptive effect of PAR-4-AP disappeared when was administrered IP, or with the blockade of colonic epithelial tight junctions, suggesting that PAR-4-AP needs to reach directly the nerve terminals in the colon. The CRD-induced spinal Fos overexpression was reduced by $43 \%$ by PAR-4-AP. The PAR-4-AP was antihyperalgesic in both hyperalgesia models and in mice with impaired lymphocytes. The PAR-4-antagonist
\end{abstract}

Address for Correspondence

Helene Eutamene, 180 Chemin de Tournefeuille, 31931

Toulouse Cedex 9, BP 3, France.

Tel: +33 5612851 59; fax: +33 5612851 45;

e-mail: heutamen@toulouse.inra.fr

Received: 20 June 2011

Accepted for publication: 30 September 2011 significantly increased the TNBS, but not the WAS-induced colonic hyperalgesia. Conclusions et Inferences The antinociceptive effect of PAR-4-AP depends on its penetration to the colonic mucosa. The PAR-4 activation is endogenously involved as a feedback loop to attenuate inflammatory colonic hyperalgesia to CRD.

Keywords proteinase-activated receptor, TNBS, visceral pain.

Abbreviations: Cat-G cathepsin G; CRD colorectal distension; DRG dorsal root ganglion; IBS-D diarrheapredominant irritable bowel syndrome; IC intracolonically; IP intraperitoneally; MPO myeloperoxidase; P4pal-10 N-palmitoyl-SGRRYGHALR-NH2; PAR-4 proteinaseactivated receptor-4; PAR-4-AP PAR-activating peptide; SC subcutaneous; SCID severe combined immunodeficiency; TAP 2,4,6-triaminopyrimidine; TNBS 2,4,6-trinitrobenzene sulfonic acid; WAS water avoidance stress.

\section{INTRODUCTION}

Proteinase-activated receptors (PARs), a family of 7-transmembrane G-protein-coupled receptors are activated by the cleavage of their $\mathrm{N}$-terminal domain by serine-proteases, which unmasks a new amino terminal sequence activating the receptor itself. ${ }^{1}$ The PARs other than PAR-3 can be cleaved by synthetic peptides, called PAR-activating peptides (PAR-APs), with sequences based on their tethered ligand. The molecule AYPGKF-NH $\mathrm{N}_{2}$ is a PAR-4-AP, which has no effect on either PAR-1 or PAR- $2,{ }^{1}$ and whose effects are blocked by a PAR-4 antagonist. ${ }^{2}$

The PARs play an important role in gastrointestinal physiology and pathophysiology ${ }^{3}$ and are 
involved in the sensation of visceral pain. The PAR-2 activation induces colorectal hypersensitivity to distension in rats, ${ }^{4}$ and its activation by high level of serine-proteases is likely to contribute to the pathogenesis of diarrhea-predominant irritable bowel syndrome (IBS-D). Indeed fecal supernatants from IBS-D patients induce colorectal hypersensitivity to distension in mice via PAR-2 activation. ${ }^{5}$ Unexpectedly, fecal supernatants from ulcerative colitis patients, containing similar elevated level of serineproteases as IBS-D patients decrease colorectal sensitivity in the same model through a predominant activation of PAR-4, overriding PAR-2 activation. ${ }^{6}$ Further, cathepsin-G (Cat-G), a PAR-4 activator contained in neutrophil granulocytes is highly present in this fecal supernatant, and was identified as promoting such colonic hyposensitivity. ${ }^{6}$ Despite its direct proinflammatory properties in the gut associated with increased colonic permeability, ${ }^{7}$ luminal activation of colonic PAR-4 by its agonist peptide PAR-4-AP produces similar visceral analgesia to colorectal distension (CRD) in mice. ${ }^{6}$ The PAR-4AP has been detected on the colonic epithelium, ${ }^{8}$ but also in dorsal root ganglion (DRG) neurons ${ }^{9}$ or immunocytes. ${ }^{10}$ Therefore, the localization of the receptors participating in the antinociceptive effect is not clear. Hence, we have first tested if intraperitoneal (IP) administration of PAR-4-AP is able to mimic the hyposensitivity seen after intracolonic (IC) infusion. Despite the presence of PAR-4 on apical site of colonocytes, due to its small size ( $<15 \mathrm{kDa})$ PAR-4-AP may be absorbed through tight junctions to reach mucosal nerve terminals. Consequently, we evaluated if the blockade of colonic epithelial tight junctions may change the effect of PAR-4-AP IC infusion. As a next step, to test if colonic lymphocytes are involved in the mechanism we used SCID mice which bear with functionally defective $\mathrm{T}$ and $\mathrm{B}$ cells due to a mutation in the Prkdc gene. ${ }^{11}$ In our previous study, the activation of colonic PAR-4 was analgesic in mice in basal conditions, ${ }^{6}$ nevertheless, in colitis, fecal Cat-G may be in contact with inflamed mucosa, where hyperalgesic neuromodulators are highly present. To evaluate a possible antihyperalgesic effect, PAR-4 agonist and Cat-G were also tested in inflammatory (2,4,6-trinitrobenzene sulfonic acid, TNBS) and noninflammatory (water avoidance stress, WAS) models of colorectal hypersensitivity to distension. In addition, the use of a selective antagonist in these conditions may allow us to detect a possible physiologic analgesic role of PAR-4, in such conditions.

\section{MATERIALS AND METHODS}

\section{Animals}

The 8-9 week-old (21-23 g) C57BL/6J wild-type male mice, BALB/ cBy Prkdc ${ }^{\text {scid }}$ (SCID) mice and their BALB/cBy controls (Janvier, Le Genest St-Isle, France) were used in our study. The animals were kept in polypropylene cages in a temperature-controlled room with a 12-h dark-light cycle, water and standard pellets were provided ad libitum. All experimental procedures were approved by both the local Institutional and the Midi Pyrenées Animal Care and Use Committees.

\section{Visceral pain measurement}

Under anesthesia (xylasine + ketamine, both $1.2 \mathrm{mg} \mathrm{SC}$ in $0.07 \mathrm{~mL}$ in $0.9 \% \mathrm{NaCl}$ ) two nickel-chrome electrodes (diameter: $0.08 \mathrm{~mm}$ ) were implanted in the abdominal external oblique muscle and the third in the abdominal skin as described previously. ${ }^{6}$ On the $4-7$ th postoperative days, colorectal distensions were performed as painful stimuli to evoke abdominal electromyographic response as a sign of visceral sensitivity. The animals were placed in a plastic tunnel, and after $1 \mathrm{~h}$ of habituation period, mice were lightly anaesthetized by sodium pentobarbital $(1 \mathrm{mg}$ in $0.15 \mathrm{~mL} 0.9 \% \mathrm{NaCl}, \mathrm{IP})$, and polyethylene perfusion and distension catheters (Fogarty catheter for artherial embolectomy, 4F, balloon length: $1.1 \mathrm{~cm}$, Edwards Lifesciences, Nijmegen, The Netherlands) were inserted into the colon (the tip of the catheters situated at 3.5 and $2.5 \mathrm{~cm}$ from the anus, respectively). ${ }^{5,6}$ Colorectal infusions were started when mice recovered completely from anesthesia (e.g. in $<60 \mathrm{~min}$ ). The CRD procedure was performed with volumes progressively increasing in $0.02 \mathrm{~mL}$ steps from 0 to $0.10 \mathrm{~mL}$, by injecting physiologic saline to the balloon with a Hamilton syringe $(500 \mu \mathrm{L}$, Hamilton Company, Bonaduz, Switzerland), each step lasting $10 \mathrm{~s}$ with $5 \mathrm{~min}$ nondistension periods in-between. During the distension periods, the abdominal muscle electrical activity was recorded and analyzed with Powerlab Chart 5 program from AD instruments. Basal EMG activity was subtracted from the EMG activity registered during the periods of distension.

\section{Elucidation of mechanism of action}

Effect of IC VS IP PAR-4 activating peptide on colorectal sensitivity Mice received PAR-4-AP (AYPGKF-NH ${ }_{2}$, Sigma, St Quentin Fallavier, France; $100 \mu \mathrm{g}$ in $0.15 \mathrm{~mL} 0.9 \% \mathrm{NaCl}$ ) or its vehicle in IP bolus injection or in IC infusion. Visceral sensitivity measurements started $1 \mathrm{~h}$ following the end of IC infusion and 15 min after the IP administration.

Effect of the tight junction blocker TAP on PAR-4 activationinduced hyposensitivity Mice received 2,4,6-triaminopyrimidine (TAP, Sigma; total dose: $30 \mu \mathrm{mol}$ per mouse in $0.1+0.15 \mathrm{~mL}$ $0.9 \% \mathrm{NaCl}$ ) IC $1 \mathrm{~h}$ preceding PAR-4-AP IC infusion (as previously described), followed by a parallel administration of IC TAP. Visceral sensitivity measurements started $1 \mathrm{~h}$ following the end of infusion.

SCID mice Male SCID mice and their BALB/cBy controls were operated as $\mathrm{C} 57 \mathrm{BL} / 6 \mathrm{~J}$ mice, and on the 4 th postoperative day mice received IC infusion of $100 \mu \mathrm{g}$ PAR-4-AP or vehicle as described above. Visceral pain measurements started $1 \mathrm{~h}$ following the end of infusion. 


\section{Visceral hypersensitivity models}

Water avoidance stress model Modification of a previously described protocol has been used. ${ }^{12}$ Briefly, C57BL/6J mice were placed on a $3 \times 3 \mathrm{~cm}$ platform in a $40 \times 40 \mathrm{~cm}$ size pool filled with tapwater for $1 \mathrm{~h}$ on four consecutive days. The animals who fell into the water were gently dried with a towel and placed back to the platform.

Colonic microinflammation Low-grade colonic inflammation was provoked by IC administration (tip of the catheter $3.5 \mathrm{~cm}$ from the anus) of a low dose of TNBS (Sigma, $20 \mathrm{mg} \mathrm{kg}^{-1}$ mice) in $40 \mu \mathrm{L} 30 \%$ ethanol or $0.9 \% \mathrm{NaCl}$ in $\mathrm{C} 57 \mathrm{BL} / 6 \mathrm{~J}$ mice on the 4 th postoperative day, as described earlier. ${ }^{13}$ Visceral sensitivity measurements were performed $72 \mathrm{~h}$ after the administration of TNBS. To assess the low-grade colonic inflammation level, myeloperoxydase activity assays were performed.

Myeloperoxidase activity assay Myeloperoxidase (MPO) activity, a marker of polymorphonuclear neutrophil granules, was assessed in colonic tissues according to previously described techniques (Bradley et al., 1982) and measured to provide an index of neutrophil infiltration and intestinal inflammation. Protein concentration was assessed using BCA protein assay kit (Interchim, Montlucon, France) and MPO activity was expressed as units per $g$ of protein.

Treatments One group of WAS and TNBS mice received IC infusion of $100 \mu \mathrm{g}$ PAR-4-AP or its vehicle and visceral sensitivity was measured $1 \mathrm{~h}$ after the end of infusion. Next group of WAS- and TNBS-treated animals were IC infused by 0.025 UN of Cat-G (Sigma, $0.167 \mathrm{UN} \mathrm{mL}^{-1}$ in $0.15 \mathrm{~mL} 0.9 \% \mathrm{NaCl}$ ) or its vehicle and CRD was performed similarly $1 \mathrm{~h}$ after the end of infusion. Another group was treated with $0.75 \mathrm{mg} \mathrm{kg}^{-1}$ PAR-4 antagonist (P4pal-10, pepducin, NeoMPS, Strasbourg, France; $\mathrm{N}$-palmitoyl-SGRRYGHALR- $\mathrm{NH}_{2}$ in $0.15 \mathrm{~mL} 0.9 \% \mathrm{NaCl}$ ) or its vehicle IP, and the response to CRD was tested $30 \mathrm{~min}$ after the injection.

Cat-G activity in the feces Following the fourth water avoidance session in the WAS model or $72 \mathrm{~h}$ after the administration of TNBS in the colitis model, fecal samples of mice were collected for Cat-G activity measurement, and fecal supernatants were prepared ( $0.3 \mathrm{~g}$ feces in $4 \mathrm{~mL} 20 \mathrm{mmol} \mathrm{L}^{-1}$ Tris $\mathrm{HCl}$, $\mathrm{pH}$ : 8.3). Cat$G$ activity in the fecal supernatant was measured by an enzymatic assay as described previously using $N$-succinyl-Ala-Ala-Pro-Phe p-Nitroanilide (Sigma). ${ }^{6}$

\section{Fos immunohistochemistry}

Mice received IC PAR-4-AP infusion $(100 \mu \mathrm{g}$ in $0.15 \mathrm{~mL} 0.9 \%$ $\mathrm{NaCl}$ ) or its vehicle, $0.9 \% \mathrm{NaCl}$ and $1 \mathrm{~h}$ later underwent the CRD protocol as described above. A group of mice without treatment and distension served as naive controls. One hour after the completion of the CRD, mice were deeply anesthetized with xylazine-ketamine (both $2 \mathrm{mg} \mathrm{IP}$ ) and perfused transcardially with $50 \mathrm{~mL}$ physiologic saline followed by $50 \mathrm{~mL}$ of $4 \%$ paraformaldehyde. After fixation, lumbosacral segments (L5-S1) of the spinal cord were dissected and removed, postfixed at $+4{ }^{\circ} \mathrm{C}$ in $4 \%$ buffered paraformaldehyde, incubated in $30 \%$ sucrose $(24 \mathrm{~h}$, $+4{ }^{\circ} \mathrm{C}$ ), embedded (Tissue Tek medium) and frozen in isopentane at $-45^{\circ} \mathrm{C}$. Frozen serial sections $(35 \mu \mathrm{m})$ were collected in phosphate-buffered saline (PBS), then rinsed twice. Sections were stained for Fos-like immunoreactivity using biotin-avidin- peroxidase complex. Briefly, sections were incubated at room temperature in a blocking solution for $30 \mathrm{~min}$ and then incubated with rabbit polyclonal Fos antibody diluted in blocking solution (1: 10 000; Ab-5, AbCys, Paris). The incubated sections were washed twice and incubated with biotinylated goat anti-rabbit secondary antibody, diluted $1: 1000$ in blocking solution, and then incubated with the avidin-biotin complex (Vectastain Elite kit; Vector Laboratories, Paris, France). Peroxidase activity was revealed using diaminobenzidine as chromogene (DAB substrate kit, Vector Laboratories, France). The presence of Fos immunoreactivity was detected as a dark brown reaction product in cell nuclei under a light microscope (90i Nikon, Nikon France, Champigny-sur-Marne, France). The number of cells containing Fos immunoreactivity was counted in the laminae I-II and the area surrounding the central canal (area X) bilaterally in 16 consecutive sections of the lumbosacral segment of the spinal cord (L5-S1), using Lucia G4.8 software.

\section{Statistical analysis}

Results are presented as means \pm SEM. Data analysis was performed by using Graphpad Prism software (Graph Pad, La Jolla, CA, USA). For the statistical analysis of MPO results, Student $t$-test was used to compare the two groups (control vs TNBS). Data obtained in fecal Cat-G activity and Fos immunohistochemistry measurements were compared by analysis of variance, followed by Tukey post hoc test. In the visceral pain experiments, means were calculated for each volume from all values in a group receiving the same treatment, and data were compared by analysis of variance, followed by Tukey post hoc test.

\section{RESULTS}

\section{Comparative influence of IC vs IP administration of PAR-4-AP on colorectal sensitivity to distension}

When infused intracolonically prior to distension, PAR-4-AP $(100 \mu \mathrm{g})$ triggered a hyposensitivity to CRD at the distension volumes from 0.04 to $0.08 \mathrm{~mL}$ compared with vehicle infusion $(P<0.05)$. In contrast, when injected intraperitoneally at the same dose, PAR-4-AP had no effect on the response to CRD $(P>0.05)$ compared with vehicle. Indeed, abdominal response to CRD after PAR-4-AP administration was significantly different between IC and IP routes at the same distension volumes $(P<0.05$; Fig. $1 \mathrm{~A})$.

\section{Effects of TAP on PAR-4-AP evoked hyposensitivity}

The colorectal infusion of TAP blocked the hyposensitive effect of PAR-4-AP IC infusion (Fig. 1B). The PAR-4-AP alone decreased the sensitivity by $54-33 \%$ at distension volumes of $0.04-0.08 \mathrm{~mL}$, respectively $(P<0.05)$. On the contrary, PAR-4-AP + TAP did not affect the sensitivity compared with vehicle $(P>0.05)$. 

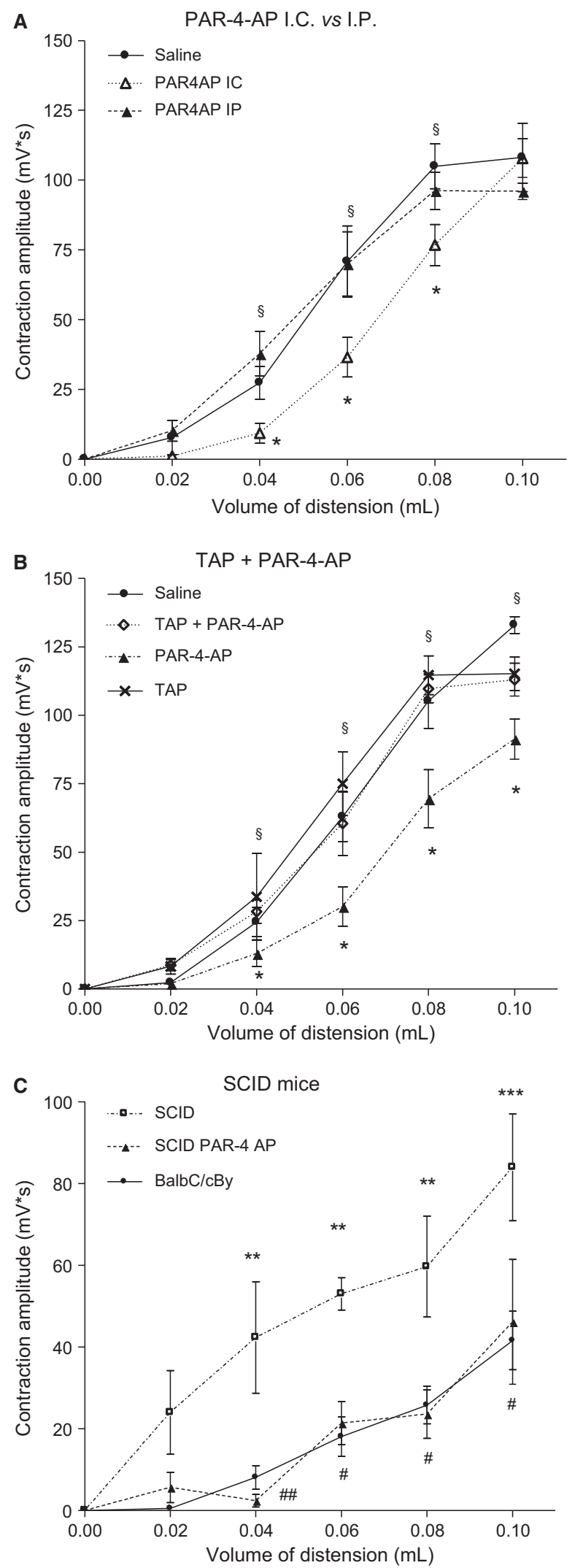

Figure 1 Effect of PAR-4-AP on visceral sensitivity by IP administration, in combination with tight junction blockade or in SCID mice. Electromyographic activity of abdominal muscle contractions evoked by CRD in mice after IP injection or IC infusion of $100 \mu \mathrm{g}$ PAR-4-AP or its vehicle, $0.9 \%$ saline. Each line represents the mean EMG response of all animals tested in the same group. (A) PAR-4-AP was antinociceptive by IC $\left(n=12,{ }^{\star} P<0.05\right)$, but not by IP $(n=9, P>0.05)$ route at the distension levels from 0.04 to $0.08 \mathrm{~mL}$ compared with saline $(n=8)$. The abdominal EMG response was significantly different between IC and IP routes at these distension volumes $\left({ }^{\S} P<0.05\right)$. (B) The blockade of tight junctions by TAP abolished the antinociceptive effect of intracolonic PAR-4-AP (PAR-4-AP, $n=9$, vs PAR-4-AP + TAP, $n=12$; ${ }^{\S} P<0.05$; whereas PAR-4-AP vs saline, $\left.n=8,{ }^{\star} P<0.05\right)$. The TAP alone had no effect on colorectal sensitivity (TAP, $n=8$ vs saline, $P>0.05$ ). (C) SCID mice $(n=7)$ were significantly hypersensitive to CRD compared with their BalbC/cBy controls $\left(n=8 ;{ }^{\star \star} P<0.01,{ }^{\star \star \star} P<0.001\right)$, which was reversed by PAR-4 activation $\left(n=8 ;{ }^{\#} P<0.05 ;{ }^{\# \#} P<0.01\right)$.

The TAP alone had no effect on colorectal sensitivity $(P>0.05)$.

\section{SCID mice}

Postoperative complications and mortality was not different in SCID mice compared with their Balb/cBy controls. Compared with their BALB/cBy controls, SCID mice had a significantly greater abdominal response to CRD at the distension levels of 0.04 to $0.1 \mathrm{~mL}$ increasing the intensity of EMG response by $384 \%$ to $132 \%$, respectively $(P<0.01 ; \quad P<0.01$; $P<0.01 ; P<0.001)$. PAR-4 activation effectively reversed this hypersensitivity $(P<0.01, \quad P<0.05$; $P<0.05 ; P<0.05$; Fig. 1 C) .

\section{Influence of PAR-4-AP and PAR-4 antagonist on WAS-induced colorectal hypersensitivity}

Water avoidance stress significantly increased visceral sensitivity to distension by $730 \%, 119 \%$, and $69 \%$, at distension volumes of $0.02,0.04$, and $0.06 \mathrm{~mL}$, respectively $(P<0.01, P<0.05, P<0.05$, Fig. $2 \mathrm{~A})$. Intracolonic infusion of PAR-4-AP before distension suppressed the colonic hypersensitivity to distension and restored it to the baseline at all distension volumes. Further, the PAR-4 antagonist had no impact on the visceral hypersensitive response to CRD observed in stressed mice (Fig. 2B).

\section{Influence of PAR-4-AP and PAR-4 antagonist on TNBS-induced colorectal hypersensitivity}

Seventy-two hours after intracolonic infusion of TNBS, the abdominal response to CRD was enhanced by $1529 \%, 98 \%$, and $90 \%$ at distension volumes of 0.02 , 0.04 , and $0.06 \mathrm{~mL}$, respectively, when compared with controls without TNBS $(P<0.001, P<0.05, P<0.01$, Fig. 3A). Intracolonic infusion of PAR-4-AP, prior to 

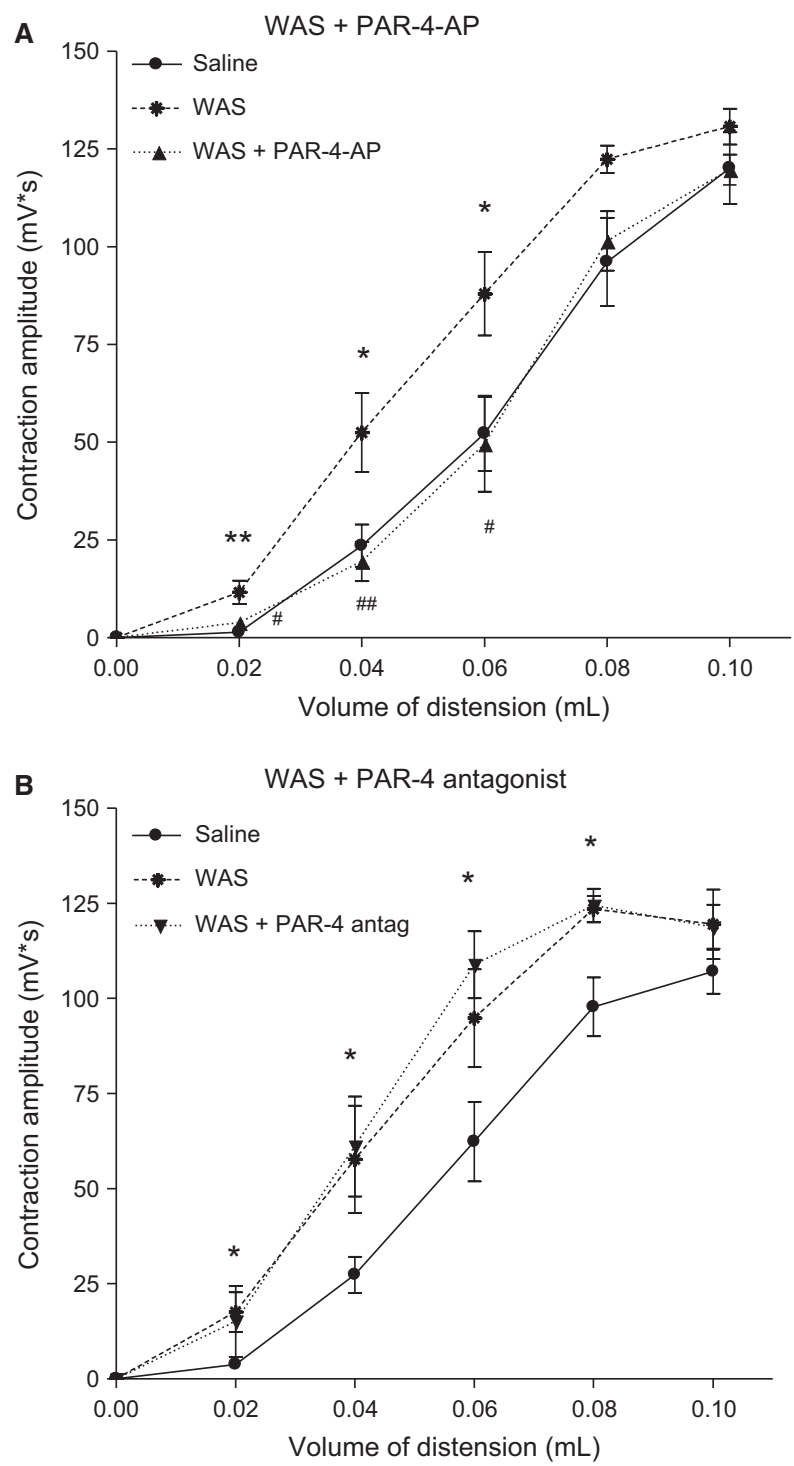

Figure 2 Effect of PAR-4 activation and blockade in water avoidance stress model. Electromyographic activity of abdominal muscle contractions evoked by CRD in mice either $1 \mathrm{~h}$ after colorectal infusion of $100 \mu \mathrm{g}$ PAR-4-AP or its vehicle, or $30 \mathrm{~min}$ after PAR-4 antagonist IP injection in water avoidance stress. Each line represents the mean EMG response of all animals tested in the same group. (A) Water avoidance stress increased sensitivity to CRD shown by the elevation in the EMG activity (WAS, $n=11$ vs saline, $n=10,{ }^{\star} P<0.05$, ${ }^{\star \star} P<0.01$ ), which was abolished by PAR-4-AP infusion (WAS vs WAS + PAR-4-AP; $n=12,{ }^{\#} P<0.05,{ }^{\# \#} P<0.01$ ). (B) PAR-4 antagonist $(n=10)$ did not change the visceral hypersensitivity provoked by water avoidance stress (saline vs WAS, ${ }^{\star} P<0.05$ ).

distension suppressed the increased sensitivity to CRD for all volumes. Unexpectedly, treatment with the PAR-4 antagonist increased the TNBS-induced hypersensitivity by $78 \%, 42 \%$, and $19 \%$ at distension volumes of $0.04,0.06$, and $0.08 \mathrm{~mL}$ compared with TNBS alone $(P<0.05, P<0.05, P<0.05$; Fig. $3 B)$.

\section{Influence of Cat-G on WAS and TNBS-induced colorectal hypersensitivity}

The intracolonic infusion of Cat-G significantly decreased the hypersensitivity observed in WAS-treated mice at volumes from 0.02 to $0.08 \mathrm{~mL}(P<0.05$; $P<0.05 ; P<0.01, P<0.01$; Fig. 4A). Surprisingly, Cat$G$ could not reverse the visceral hypersensitivity induced by low-grade TNBS inflammation (saline vs TNBS + Cat-G; $P<0.05$ at the distension volumes of 0.04 and $0.06 \mathrm{~mL}$ and $P<0.01$ at the volume of $0.08 \mathrm{~mL}$; Fig. 4B).

\section{Cathepsin-G activity in feces of mice after WAS} and TNBS treatment

Cat-G activity was significantly increased in feces of mice with TNBS colitis $\left(17.0 \pm 2.6 \mathrm{U} \mathrm{mg}^{-1}\right.$ prot $)$ compared with naïve controls $\left(8.8 \pm 1.9 \mathrm{U} \mathrm{mg}^{-1}\right.$ prot). In contrast, Cat-G activity was not elevated in the feces of stressed mice compared with naïve controls $\left(6.9 \pm 2.5 \mathrm{U} \mathrm{mg}^{-1}\right.$ prot, $P>0.05$; Fig. $\left.3 \mathrm{C}\right)$.

\section{Evaluation of colonic inflammation induced by a low dose of TNBS}

Three days after intracolonic instillation, a low dose of TNBS $\left(20 \mathrm{mg} \mathrm{kg}^{-1}\right)$ induces a slight, but a significant increase of MPO in TNBS mice compared with control $(12.7 \pm 2.1$ vs $8.34 \pm 1.2$, respectively; Fig. 3D). This slight elevated MPO activity was also associated to a slight mucosal thickening in TNBS mice compared with control and to a slight body weight loss 3 days after intracolonic TNBS instillation (Table 1).

\section{Effects of PAR-4-AP on the CRD-induced spinal Fos expression}

In naïve mice, the number of Fos-positive cells in the L5-S1 levels of the spinal cord was $7.4 \pm 0.7$ per section. This number was markedly increased (4.9fold) after CRD in the group treated with saline compared with naïve, undistended animals $(P<0.001$; Fig. 5A, B). However, pretreatment with PAR-4-AP IC infusion reduced the CRD-induced Fos expression increase by $46 \%$ in the spinal cord compared with saline $(P<0.001$; Fig. 5A, B).

\section{DISCUSSION}

In addition to our previous data showing the antinociceptive effect of intracolonic PAR-4-AP ${ }^{6}$ confirmed by others, ${ }^{14}$ this work demonstrates that this effect is 

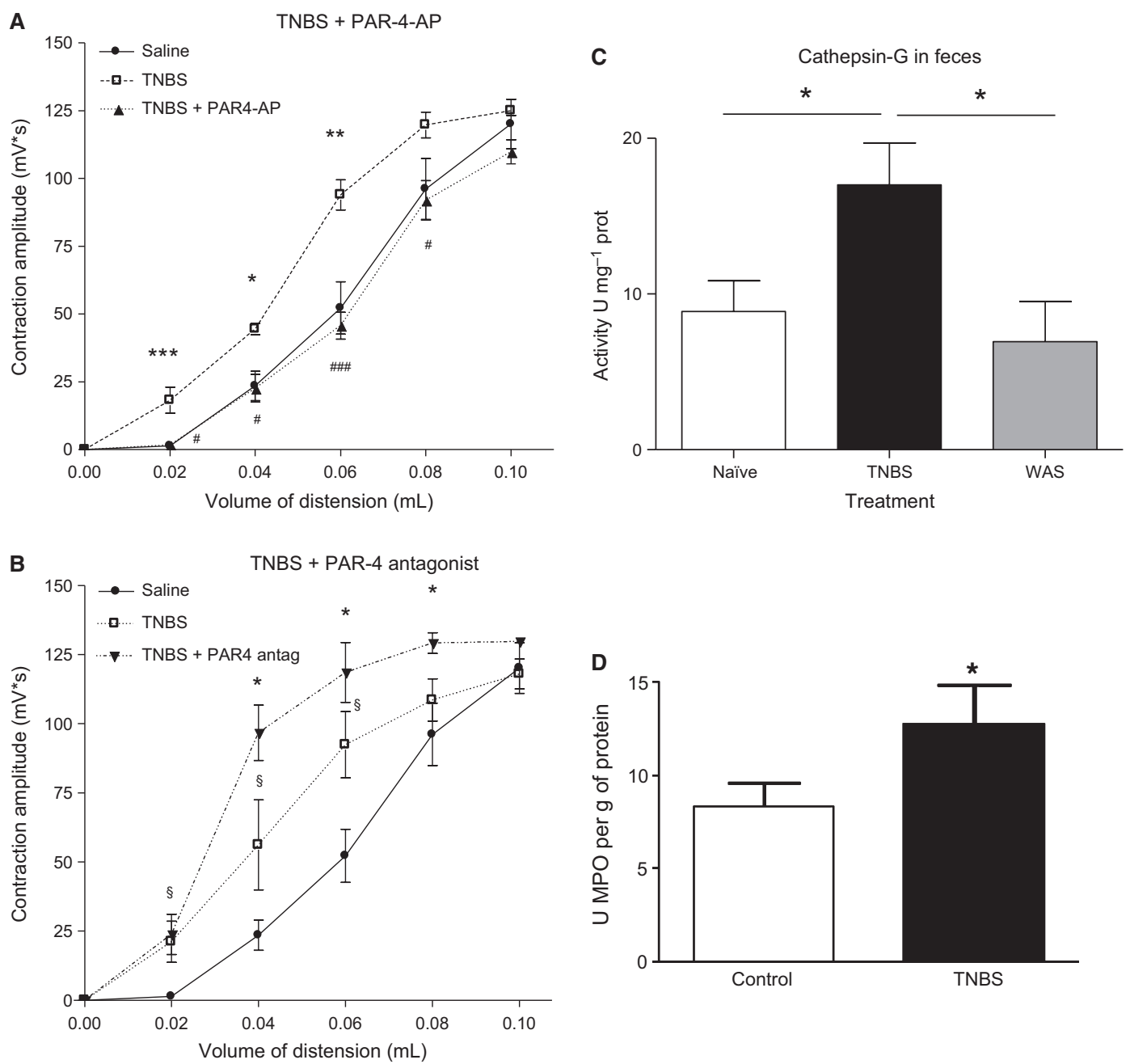

Figure 3 Effect of PAR-4 activation and blockade in TNBS-induced hypersensitivity. Electromyographic activity of abdominal muscle contractions evoked by CRD in mice either $1 \mathrm{~h}$ after colorectal infusion of $100 \mu \mathrm{g}$ PAR-4-AP or its vehicle, or 30 min after PAR-4 antagonist IP injection in TNBS-induced hypersensitivity. Each line represents the mean EMG response of all animals tested in the same group. (A) $72 \mathrm{~h}$ after TNBS IC infusion, EMG activity evoked by distension was increased at distension volumes from 0.02 to $0.06 \mathrm{~mL}$, respectively demonstrating higher colorectal sensitivity (TNBS, $n=12$ vs saline, $n=10,{ }^{\star} P<0.05,{ }^{\star \star} P<0.01 ;{ }^{\star \star \star}{ }^{\star} P<0.01$ ). PAR-4-AP infusion reversed the effect (TNBS VS TNBS + PAR-4-AP, $\left.n=11,{ }^{\#} P<0.05,{ }^{\# \# \#} P<0.001\right)$. (B) Interestingly, the PAR-4 antagonist $(n=9)$ augmented the hypersensitivity compared to TNBS alone (TNBS vs TNBS + PAR-4-antagonist ${ }^{\star} P<0.05$, whereas saline vs TNBS, ${ }^{\S} P<0.05$ ). (C) Cat-G activity significantly increased in feces of mice with TNBS colitis $\left(n=8,{ }^{\star} P<0.05\right)$ compared with naïve controls $(n=8)$ or WAS-treated animals $(n=10)$. There was no difference between naïve controls and stressed animals $(P>0.05)$. D) MPO activity significantly increased in the colon of mice with TNBS colitis $(n=10$, $P<0.05)$ compared with naïve controls $(n=10)$.

driven locally. Further, we provide new information on the presence of an endogenous activation of PAR- 4 in inflammatory mediated hypersensitivity acting as a feed-back mechanism controlling pain, not activated in stress-induced visceral hyperalgesia.

\section{The localization of PAR-4 responsible for the antinociceptive effect}

PAR-4 is present in the colonic epithelium, ${ }^{8}$ but also in dorsal root ganglion (DRG) neurons, where its activation does not induce a calcium signal, but reduces the calcium signal evoked by $\mathrm{KCl} .^{9}$ The involvement of PAR-4 in nociception has been shown in rat knee joint primary afferents as well. ${ }^{15}$ Further, patch clamp recordings show that PAR-4 activation in DRG neurons projecting to the colon suppresses their excitability. ${ }^{16}$ PARs are also found on the surface of different immune cells throughout the gastrointestinal tract, where their activation may trigger the release of various chemokines and growth factors, ${ }^{10}$ interfering with nociceptive pathways. Our present findings on the failure of systemic PAR-4-AP administration to reduce visceral pain sensation is in accordance with 
A

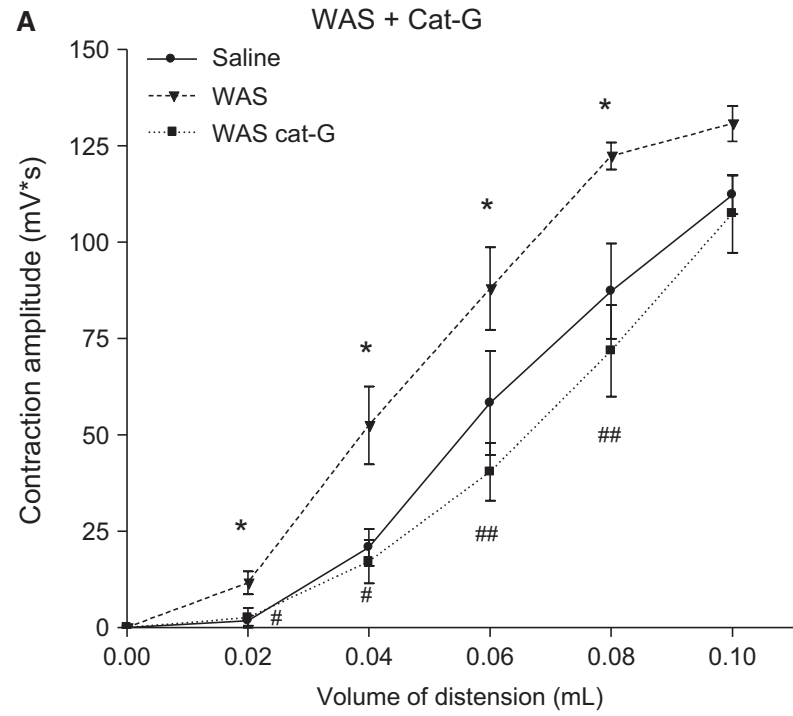

B

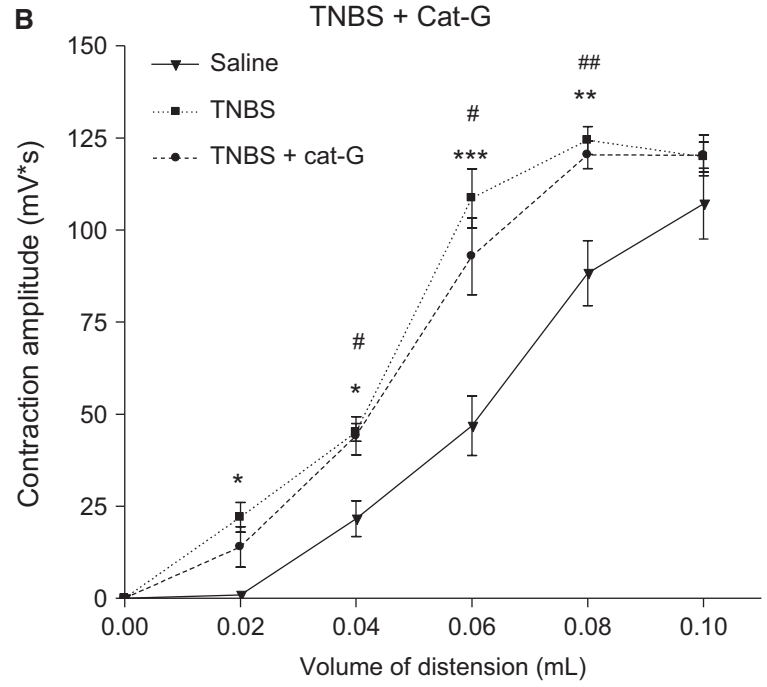

Figure 4 Effect of Cat-G in water avoidance stress and TNBS-induced colorectal hypersensitivity. Electromyographic activity of abdominal muscle contractions evoked by CRD in mice $1 \mathrm{~h}$ after colorectal infusion of $0.025 \mathrm{UN}$ of Cat-G or its vehicle. (A) Cat-G restored the basal EMG response in the WAS-induced visceral hypersensitivity demonstrating an antihyperalgesic effect (saline vs WAS, ${ }^{\star} P<0.05$; WAS vs WAS + Cat-G, $\left.{ }^{\#} P<0.05,{ }^{\# \#} P<0.01\right)$. (B) In the TNBS model, Cat-G could not influence the visceral hypersensitivity (saline vs TNBS, ${ }^{\star} P<0.05,{ }^{\star \star} P<0.01,{ }^{\star \star}{ }^{\star} P<0.001$; saline vs TNBS + Cat-G, $\left.{ }^{\#} P<0.05,{ }^{\# \#} P<0.01\right)$.

previous data demonstrating that intraplantar injection of PAR-4-AP was antinociceptive in the injected paw, but not in the contralateral paw, showing a local effect. ${ }^{9}$ In addition, TAP, a tight junction blocker used for decades not only to block cation-selective permeability in various epithelial tissues ${ }^{17,18}$ but also is described as an inotropic agent which acts on potassium conductance in epithelial cell levels, suppresses the antinociceptive effect of PAR-4-AP. TAP activity is preferentially mediated directly by its binding to sites inside the tight junction cation channel. ${ }^{17}$ However, there are no in vivo studies available comparing the tight junction blocker properties of TAP and its ability to act as an inotropic agent of potassium conductance in epithelial cells. In addition, using TAP agent, a clear link between epithelial intestinal permeability impairment and visceral pain development was described in a rat model of acute stress. ${ }^{19}$ This positive correlation is now well established in IBS patients with hypersensitivity, as high visceral pain criterion in these patients is positively correlated with increased intestinal permeability. ${ }^{20,21}$ Therefore, taken together, these data suggest that the responsible receptors explaining the antinociceptive effect of PAR-4-AP are located beyond the epithelial cell layer. Nevertheless, the PAR-4-AP elicited increase in colonic permeability ${ }^{7}$ is not associated with an increase, but a decrease of nociception, still, the increase of permeability does not rule out the antinociceptive effect.

The PAR-4 is expressed by Kupffer cells, B-lymphocytes $^{22}$ and mast cells, ${ }^{23}$ and its activation affects leukocyte mobility. ${ }^{24,25}$ Our results show that colonic lymphocytes do not play a role in the antinociceptive effect of PAR-4-AP. Indeed, SCID mice were found hyperalgesic to $\mathrm{CRD}^{26}$ and reconstitution of the mice with CD4 $+\mathrm{T}$ cells restored visceral pain sensation within the normal limits. The antinociceptive effect of PAR-4-AP is still present in SCID mice suggesting that such action does not require functional $\mathrm{B}$ or $\mathrm{T}$ cells. However, the involvement of other immune cells, like macrophages cannot be excluded with the use of SCID mice, indeed, PAR-4 has been described on the macrophages of rats. ${ }^{27}$ Incidentally, we have observed that Balb/cBy mice are hyposensitive in our model of CRD compared with C57BL/6J mice. Strain differences has been described earlier in different experimental models in terms of susceptibility to colitis ${ }^{28,29}$ or in antinociceptive responsiveness to $\mathrm{N}_{2} \mathrm{O} .^{30}$ These data suggest the presence of anatomic and/or functional differences in the immune and neurologic system of these mice strains, which may explain the observed dissimilarity in their response to colorectal distension.

Induction of Fos expression is a marker of neuronal activation, and CRD is a well-known stimulus to activate primary visceral sensory afferents ${ }^{31}$ projecting to the lumbosacral spinal cord in mice (L5-S1). ${ }^{32}$ CRD induces Fos expression bilaterally in the L6-S2 spinal segments particularly in laminae I and II located in the dorsal horn. We observed a Fos protein overexpression in mice after CRD in the L5-S1 segments of the spinal cord. Parallel to the decreased sensitivity to CRD, 
Table 1 Low-grade inflammatory effect of $20 \mathrm{mg} \mathrm{kg}^{-1}$ TNBS in 30\% ethanol intracolonically infused in C57BL/6J mice

\begin{tabular}{|c|c|c|c|c|}
\hline & $\begin{array}{l}\text { Control mice } \\
\text { (day 0) }\end{array}$ & $\begin{array}{l}\text { Control mice } \\
\text { (day 3) }\end{array}$ & $\begin{array}{l}\text { TNBS mice before TNBS } \\
\text { instillation (day } 0 \text { ) }\end{array}$ & $\begin{array}{l}\text { TNBS mice after TNBS } \\
\text { instillation (day } 3)\end{array}$ \\
\hline Body weight (g) & $22.7 \pm 0.25$ & $22.9 \pm 0.35$ & $23.3 \pm 0.18$ & $22.9 \pm 0.22 \#$ \\
\hline Colonic length $(\mathrm{cm})$ & - & $7.93 \pm 0.20$ & - & $7.8 \pm 0.08$ \\
\hline $\begin{array}{l}\text { Macroscopic damage } \\
\text { score (colonic mucosal } \\
\text { thickening) }\end{array}$ & - & $0 \pm 0$ & - & $0.5 \pm 0.02^{\star}$ \\
\hline
\end{tabular}

TNBS, 2,4,6-trinitrobenzene sulfonic acid.

Note only a slight colonic mucosal thickening compared with control and also a slight body weight loss of mice 3 days after TNBS instillation. Mean \pm SEM $(n=10) .{ }^{\star} P<0.05$ from control mice (day 3$) ;{ }^{*} P<0.05$ from mice before TNBS instillation (day 0$)$.

A
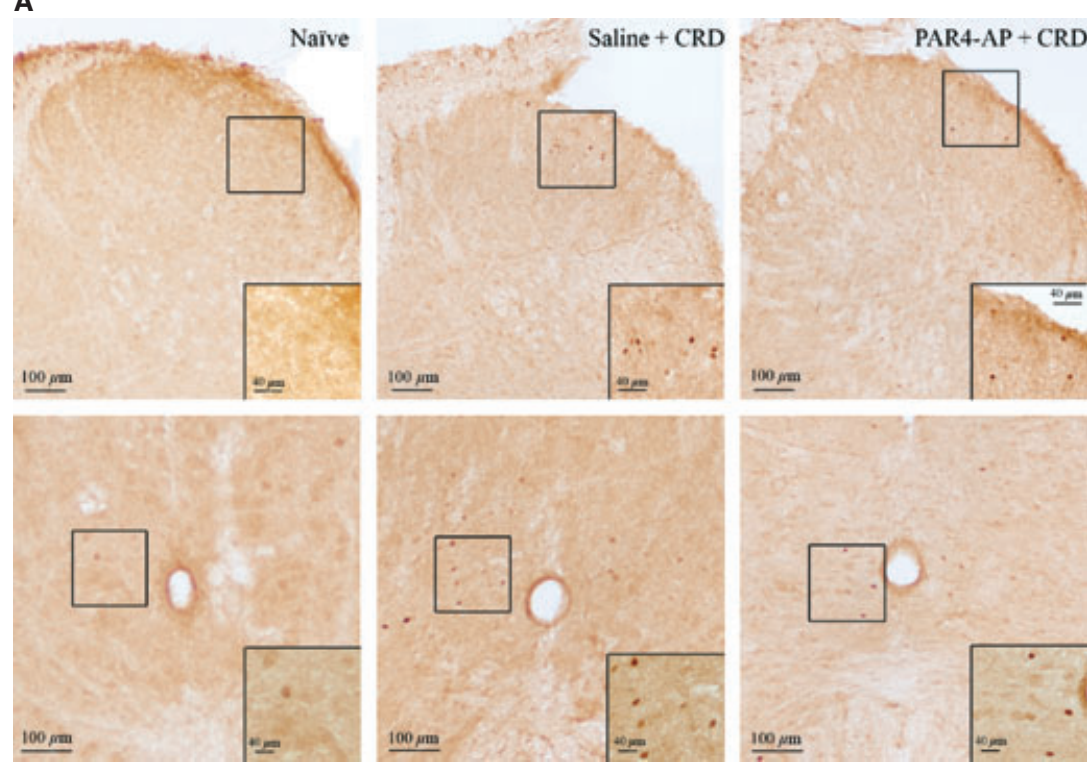

\section{B}

C-fos in the spinal cord L5-S1 segment

***

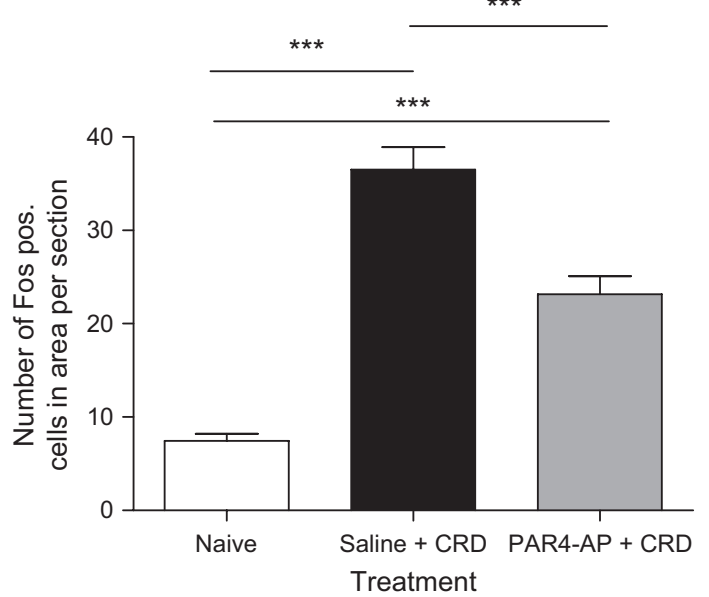

Figure 5 Effect of PAR-4 activation on CRD-induced Fos expression in the spinal cord. (A) Fos immunostaining (arrowheads) of dorsal horn and central area of the spinal cord (segment L5) in naive, undistended animals $(n=5)$, and after CRD in vehicle $(n=5)$ or PAR-4 AP-treated $(n=5)$ mice. (B) Fos expression increased significantly in the lumbosacral spinal cord after CRD in the group treated with $0.9 \%$ saline $(P<0.001)$, whereas PAR-4-AP decreased this CRD-induced Fos expression $(P<0.001)$. 
PAR-4-AP attenuates Fos expression in the lumbosacral spinal cord. This finding confirms that a decreased neuronal activation is present behind the observed hypoalgesia to CRD.

\section{Endogenous antinociceptive role of PAR-4 in inflammatory, but not non-inflammatory visceral hyperalgesia}

The PAR-1 and PAR-4 activation exert analgesic effect to thermal and mechanical stimuli in a rat somatic pain model in both basal and inflammatory conditions. ${ }^{9,33}$ Further, PAR-4 activation has been shown to reverse PAR-2 or TRPV-4 activation-induced colorectal hypersensitivity in mice. ${ }^{14}$ Herein, we have extended these observations to two visceral hypersensitivity models. Stress is followed by the activation of colonic mast cells ${ }^{34}$ responsible for a colonic barrier dysfunction. ${ }^{35}$ In contrast, in inflammatory hyperalgesia (colitis) model, inflammatory mediators, such as bradykinin can participate to the higher response to colonic distension. ${ }^{36}$ Our results demonstrate that despite the different origins of colorectal hyperalgesia, PAR-4-AP exerts similar antihyperalgesic effects.

Surprisingly, in the TNBS colitis model the colorectal hyperalgesia was augmented by blocking PAR-4 with an antagonist. This suggests the presence of an endogenous activation of PAR-4 in colonic inflammation, exerting a feed-back antinociceptive effect, which was not observed in the stress model. One explanation may be that in TNBS colitis an invasion of neutrophil granulocytes appears in the colonic mucosa, acting as a source of inflammatory mediators, such as Cat-G, a potent activator of PAR $-4^{37}$ that reach sensitive nerve terminals and cause hyposensitivity to CRD. ${ }^{6}$ In agreement with such hypothesis, using a substrate not completely specific, but largely used as one of the most specific substrate for Cat-G activity evaluation, ${ }^{38,39}$ we found an increase of Cat-G activity in the feces associated with neutrophil infiltration in mice with low-grade TNBS colitis, but not in that of stressed mice. Taken together these data may highlight a new role of Cat-G as an endogenous PAR-4 agonist activating a feed-back loop to decrease pain in inflammatory conditions. According to the literature, we can also hypothesize that PAR-4 activated by Cat-G can exert this physiologic antinociceptive feedback loop similar to PAR-1 in inflammatory condition via the release of endogenous mediators like opioids. Indeed, PAR-1 activation modulate paw inflammatory pain by triggering the production of proenkephalin and the activation of opioid receptors. ${ }^{40}$
Besides, the intracolonic administration of Cat-G reversed the colorectal hypersensitivity in mice evoked by WAS, but not by TNBS, whereas PAR-4AP was antihyperalgesic in both models. This finding can be explained by the non-specificity of Cat-G on PAR-4. Thus, Cat-G may disarm PAR-1 and PAR-2 on human bronchial fibroblasts. ${ }^{41}$ Further, in cardiomyocytes, Cat-G induces apoptosis via a PAR-independent mechanism. ${ }^{37}$ On the other hand, inflammatory mediators released in specific conditions may alter the expression of PARs, which may affect PAR signaling locally. ${ }^{41,42}$ Namely, TNF- $\alpha$ and LPS upregulates PAR2 and induces PAR-4 mRNA expression in human bronchial fibroblasts. ${ }^{41}$ We may hypothesize that similar changes appear in TNBS-induced colonic inflammation, which alters the effects of Cat-G on PARs due to its non-specificity. Indeed, in the WAS model, where Cat-G release to the colonic wall is not relevant, the endogenous PAR-4 activation is not detectable, and extrinsic Cat-G exhibits an analgesic effect by PAR-4 activation, similar to PAR-4-AP. However, in the TNBS model, endogenous Cat-G is already highly present in the colonic wall, and activates PAR-4 to exert an analgesic effect. Although PAR-4-AP, a pure PAR-4 agonist is still antinociceptive in this model, additional extrinsic Cat-G does not reinforce the analgesic effect. This observation highlights the natural antinociceptive role of Cat-G in endogenous concentrations in the TNBS model, whereas increasing the concentration by external administration brings the non-specific effects of Cat-G to the front.

\section{CONCLUSIONS}

In summary, our results indicate that the antinociceptive effects of PAR-4-AP are linked to a direct or indirect activation of receptors located on colonic nerve terminals, and that PAR-4-AP administration is antinociceptive not only in basal, but also in stress and inflammatory conditions. Endogenous activation of PAR-4 plays an antinociceptive role in mild-TNBS colitis, but not in stress-induced visceral hyperalgesia, and Cat-G is a possible candidate to activate this endogenous antinociceptive mechanism.

\section{ACKNOWLEDGMENTS}

Anita Annahazi is a recipient of a postdoctoral fellowship from INRA. This work was supported by institutional grant from INRA and TÁMOP (TÁMOP-4.2.2-08/01-2008-0002). The authors thank Afifa Ait-Belgnaoui for her help in the methodology, and Mathilde Leveque and Patrice Rouby for their technical assistance. 


\section{AUTHOR CONTRIBUTION}

AA performed the research, analyzed the data and wrote the article. $\mathrm{MD}, \mathrm{CSC}$, and AP performed the research and prepared the figures. GK, AR, RR helped in the design of the study and the writing of the article. VT, TW, LB designed the study. HE designed the study, performed the research, analyzed the data and wrote the article.

\section{COMPETING INTERESTS}

None.

\section{REFERENCES}

1 Hollenberg MD, Compton SJ. International Union of Pharmacology. XXVIII. Proteinase-activated receptors. Pharmacol Rev 2002; 54: 203-17.

2 Houle S, Papez MD, Ferazzini M, Hollenberg MD, Vergnolle N. Neutrophils and the kallikrein-kinin system in proteinase-activated receptor 4-mediated inflammation in rodents. Br J Pharmacol 2005; 146: 670-8.

3 Kawabata A, Matsunami M, Sekiguchi F. Gastrointestinal roles for proteinase-activated receptors in health and disease. Br I Pharmacol 2008; 153(Suppl. 1): S230-40.

4 Coelho AM, Vergnolle N, Guiard B, Fioramonti J, Bueno L. Proteinases and proteinase-activated receptor 2 : a possible role to promote visceral hyperalgesia in rats. Gastroenterology 2002; 122: 1035-47.

5 Gecse K, Roka R, Ferrier L et al. Increased faecal serine protease activity in diarrhoeic IBS patients: a colonic lumenal factor impairing colonic permeability and sensitivity. Gut 2008; 57: 591-9.

6 Annahazi A, Gecse K, Dabek M et al. Fecal proteases from diarrheic-IBS and ulcerative colitis patients exert opposite effect on visceral sensitivity in mice. Pain 2009; 144: 209-17.

7 Dabek M, Ferrier L, Roka R et al. Luminal cathepsin $\mathrm{g}$ and proteaseactivated receptor 4 . A Duet involved in alterations of the colonic epithelial barrier in ulcerative colitis. Am I Pathol 2009; 175: 207-14.

8 Mule F, Pizzuti R, Capparelli A, Vergnolle N. Evidence for the presence of functional protease activated receptor 4 (PAR4) in the rat colon. Gut 2004; 53: 229-34.

9 Asfaha S, Cenac N, Houle S et al. Protease-activated receptor-4: a novel mechanism of inflammatory pain modulation. Br I Pharmacol 2007; 150: 176-85.

10 Shpacovitch V, Feld M, Bunnett NW, Steinhoff M. Protease-activated receptors: novel PARtners in innate immunity. Trends Immunol 2007; 28: 541-50.

11 Bosma GC, Custer RP, Bosma MJ. A severe combined immunodeficiency mutation in the mouse. Nature 1983; 301: 527-30.

12 Larauche M, Gourcerol G, Million M, Adelson DW, Tache Y. Repeated psychological stress-induced alterations of visceral sensitivity and colonic motor functions in mice: influence of surgery and postoperative single housing on visceromotor responses. Stress 2010; 13: 343-54.

13 Eutamene H, Bradesi S, Larauche M et al. Guanylate cyclase C-mediated antinociceptive effects of linaclotide in rodent models of visceral pain. Neurogastroenterol Motil 2010; 22: e312-84.

14 Auge C, Balz-Hara D, Steinhoff M, Vergnolle N, Cenac N. Protease-activated receptor-4 (PAR 4): a role as inhibitor of visceral pain and hypersensitivity. Neurogastroenterol Motil 2009; 21: 1189-e107.

15 Russell FA, Veldhoen VE, Tchitchkan D, McDougall JJ. Proteinase-activated receptor-4 (PAR4) activation leads to sensitization of rat joint primary afferents via a bradykinin $\mathrm{B} 2$ receptordependent mechanism. I Neurophysiol 2010; 103: 155-63.

16 Karanjia R, Spreadbury I, BautistaCruz F, Tsang ME, Vanner S. Activation of protease-activated receptor-4 inhibits the intrinsic excitability of colonic dorsal root ganglia neurons. Neurogastroenterol Motil 2009; 21: 1218-21.

17 Moreno JH. Blockage of gallbladder tight junction cation-selective channels by 2,4,6-triaminopyrimidinium (TAP). I Gen Physiol 1975; 66: $97-$ 115.

18 Moreno JH. Blockage of cation permeability across the tight junctions of gallbladder and other leaky epithelia. Nature 1974; 251: 150-1.

19 Ait-Belgnaoui A, Bradesi S, Fioramonti J, Theodorou V, Bueno L. Acute stress-induced hypersensitivity to colonic distension depends upon increase in paracellular permeability: role of myosin light chain kinase. Pain 2005; 113: 141-7.

20 Piche T, Barbara G, Aubert P et al. Impaired intestinal barrier integrity in the colon of patients with irritable bowel syndrome: involvement of soluble mediators. Gut 2009; 58: 196201.

21 Zhou Q, Zhang B, Verne GN. Intestinal membrane permeability and hypersensitivity in the irritable bowel syndrome. Pain 2009; 146: 41-6.

22 Rullier A, Senant N, Kisiel W et al. Expression of protease-activated receptors and tissue factor in human liver. Virchows Arch 2006; 448: 46-51.

23 Moormann C, Artuc M, Pohl E et al. Functional characterization and expression analysis of the proteinaseactivated receptor- 2 in human cutaneous mast cells. I Invest Dermatol 2006; 126: 746-55.

24 Cenac N, Coelho AM, Nguyen C et al. Induction of intestinal inflammation in mouse by activation of proteinase-activated receptor-2. Am I Pathol 2002; 161: 1903-15.

25 Moffatt JD, Lever R, Page CP. Effects of inhaled thrombin receptor agonists in mice. Br J Pharmacol 2004; 143: 269-75.

26 Verma-Gandhu M, Bercik P, Motomura Y et al. CD4 + T-cell modulation of visceral nociception in mice. Gastroenterology 2006; 130: 1721-8.

27 Jesmin S, Gando S, Zaedi S, Sakuraya F. Differential expression, time course and distribution of four PARs in rats with endotoxin-induced acute lung injury. Inflammation 2007; 30: 14-27.

28 Scheiffele F, Fuss IJ. Induction of TNBS colitis in mice. Curr Protoc Immunol 2002; 15.19: 1-15.

29 Melgar S, Hammarstrom S, Oberg A, Danielsson A, Hammarstrom ML. Cytolytic capabilities of lamina propria and intraepithelial lymphocytes in normal and chronically inflamed human intestine. Scand I Immunol 2004; 60: 167-77. 
30 Quock RM, Mueller JL, Vaughn LK. Strain-dependent differences in responsiveness of mice to nitrous oxide $(\mathrm{N} 2 \mathrm{O})$ antinociception. Brain Res 1993; 614: 52-6.

31 Traub RJ, Herdegen T, Gebhart GF. Differential expression of $\mathrm{c}$-fos and c-jun in two regions of the rat spinal cord following noxious colorectal distention. Neurosci Lett 1993; 160: 121-5.

32 Christianson JA, Traub RJ, Davis BM. Differences in spinal distribution and neurochemical phenotype of colonic afferents in mouse and rat. I Comp Neurol 2006; 494: 246-59.

33 Asfaha S, Brussee V, Chapman K, Zochodne DW, Vergnolle N. Proteinase-activated receptor-1 agonists attenuate nociception in response to noxious stimuli. $B r \quad I$ Pharmacol 2002; 135: 1101-6.

34 Gue M, Del Rio-Lacheze C, Eutamene $\mathrm{H}$, Theodorou V, Fioramonti J, Bueno L. Stress-induced visceral hypersensitivity to rectal distension in rats: role of CRF and mast cells.
Neurogastroenterol Motil 1997; 9: 271-9.

35 Santos J, Yang PC, Soderholm JD, Benjamin M, Perdue MH. Role of mast cells in chronic stress induced colonic epithelial barrier dysfunction in the rat. Gut 2001; 48: 630-6.

36 Couture R, Harrisson M, Vianna RM, Cloutier F. Kinin receptors in pain and inflammation. Eur I Pharmacol 2001; 429: 161-76.

37 Sabri A, Alcott SG, Elouardighi H et al. Neutrophil cathepsin G promotes detachment-induced cardiomyocyte apoptosis via a proteaseactivated receptor-independent mechanism. I Biol Chem 2003; 278: 23944-54.

38 Raymond WW, Trivedi NN, Makarova A et al. How immune peptidases change specificity: cathepsin G gained tryptic function but lost efficiency during primate evolution. I Immunol 2010; 185: 5360-8.

39 Liao $\mathrm{CH}$, Chen JJ, Lin JE et al. 5hydroxy-2-(4-hydroxy-3-methoxyphe-
nyl)-3,7-dimethoxy-4H-chromen-4-one (MSF-2) suppresses fMLP-mediated respiratory burst in human neutrophils by inhibiting phosphatidylinositol 3-kinase activity. I Cell Physiol 2011; 226: 1519-30.

40 Martin L, Augé C, Boué J et al. Thrombin receptor: an endogenous inhibitor of inflammatory pain, activating opioid pathways. Pain 2009; 146: 121-9.

41 Ramachandran R, Sadofsky LR, Xiao $\mathrm{Y}$ et al. Inflammatory mediators modulate thrombin and cathepsin-G signaling in human bronchial fibroblasts by inducing expression of proteinase-activated receptor-4. Am I Physiol 2007; 292: L788-98.

42 D'Andrea MR, Saban MR, Nguyen NB, Andrade-Gordon P, Saban R. Expression of protease-activated receptor- $1,-2,-3$, and -4 in control and experimentally inflamed mouse bladder. Am J Pathol 2003; 162: 90723. 